\title{
Aortic Arch Atherosclerosis in Ischaemic Stroke of Unknown Origin Affects Prognosis
}

\author{
Arata Abe Mina Harada-Abe Masayuki Ueda Takehiro Katano \\ Masataka Nakajima Kanako Muraga Satoshi Suda Yasuhiro Nishiyama \\ Seiji Okubo Masahiro Mishina Ken-ichiro Katsura Yasuo Katayama \\ Department of Neurological Science, Graduate School of Medicine, Nippon Medical School, \\ Tokyo, Japan
}

Key Words

Aortic arch atherosclerosis · Stroke of unknown origin · Prognosis

\section{Abstract}

Background: Cerebral infarction of unknown origin at admission accounts for half of all cerebral infarction cases in some institutions. However, the factors associated with cerebral infarction prognosis have not been sufficiently examined. Here, we investigated whether aortic arch plaques (AAPs) on transoesophageal echocardiography (TOE) were associated with the prognosis of cerebral infarction of unknown origin at admission. Methods: Of 571 patients who were hospitalised between June 2009 and September 2011, 149 (age: $67 \pm 14$ years; 95 men) with cerebral infarctions of unknown origin at admission underwent TOE and were enrolled in this study. We examined their clinical characteristics, the incidence of intermittent atrial fibrillation detected on 24-hour electrocardiography, and the echographic findings of the carotid artery in the hospital. A poor prognostic outcome was defined as a modified Rankin Scale score of $\geq 3$ after 90 days. Results: In all, 110 patients (74\%) showed good prognoses and 39 patients (26\%) showed poor outcomes. A National Institutes of Health Stroke Scale score of $>6$ on admission [odds ratio $(O R)=6.77 ; 95 \%$ confidence interval $(\mathrm{CI}): 2.59-18.8$; $p<0.001]$ and AAPs of $\geq 4 \mathrm{~mm}(O R=2.75 ; 95 \% C I: 1.19-6.91 ; p=0.024)$ showed significant associations with a poor prognosis of cerebral infarction of unknown origin at admission. Conclusions: Thick AAPs could be a factor in the prediction of a poor prognosis of cerebral infarction of unknown origin at admission. The establishment of international standards for aortogenic brain embolisms is required. Future prospective studies should examine cerebral infarctions of unknown origin. 

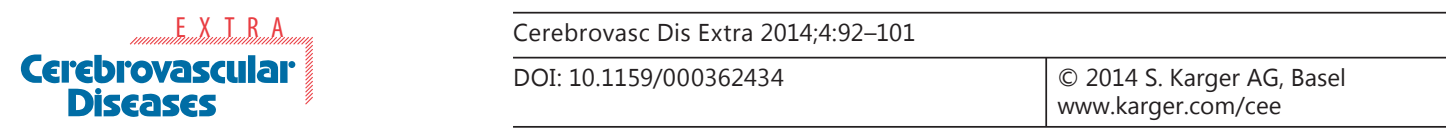

Abe et al.: Aortic Arch Atherosclerosis in Ischaemic Stroke of Unknown Origin Affects Prognosis

\section{Introduction}

Approximately half of the 50 million stroke survivors in the world rely on help provided by caregivers [1]. For patients with stroke, accurate predictions of whether they will be able to perform their basic daily living activities would be useful for optimising initial stroke treatment as well as for establishing treatment goals.

Of all cases of stroke, ischaemic stroke accounts for $70 \%$ in Asia and 85\% in Europe [2, 3]. Many studies have been performed to predict ischaemic stroke prognosis [4-8]. Although cerebral cardioembolic and lacunar infarctions have been actively investigated for their frequencies [9-11], there have been few reports on cerebral infarction of unknown origin. Among patients with cerebral infarctions, those with infarctions of unknown origin account for $35-42 \%$ [12]. However, this percentage is expected to be higher when patients are hospitalised.

An autopsy study indicated that large atheromatous aortic plaques $\geq 4 \mathrm{~mm}$ in diameter were located near the aortic arch of the chest; these plaques might be involved in cerebral infarction of unknown origin [13]. Large plaques ( $\geq 4 \mathrm{~mm}$ ) are known to be involved not only in first-ever cerebral infarction [14-16] but also in its recurrence, with an increased risk of death $[17,18]$.

The purpose of the present study was to evaluate the information obtained from transoesophageal echocardiography (TOE), particularly in association with aortic arch plaques (AAPs), as a factor in the prognosis of patients with first-ever cerebral infarction of unknown origin at admission.

\section{Methods}

\section{Study Population}

This retrospective case series was based on an analysis of data collected from a stroke registry of patients admitted to the Department of Neurological Science at Nippon Medical School Hospital between June 2009 and September 2011 for cerebral ischaemic stroke excluding intermittent ischaemic attack. At a median of $12 \mathrm{~h}$ after admission, a total of 571 patients with cerebral ischaemic stroke underwent the following examinations as routine diagnostics: brain computed tomography or magnetic resonance imaging, including diffusionweighted imaging, fluid-attenuated inversion recovery imaging, T2-weighted imaging, and magnetic resonance angiography. Carotid Doppler ultrasonography was performed with a 5- to $10-\mathrm{MHz}$ annular array transducer connected to an ultrasound imaging system (LOGIQ S6; GE Medical Systems, Milwaukee, Wisc., USA). Furthermore, each patient underwent transthoracic echocardiography and electrocardiography. Brain infarction was diagnosed as an acute neurological event persisting for $\geq 24 \mathrm{~h}$ in association with focal hyperintensity on diffusion-weighted imaging.

Based on the results, we classified infarct origins according to the Trial of Org 10172 in Acute Stroke Treatment criteria [19]. The patients were divided into those with small-vessel occlusions $(n=96)$, those with large-artery atherosclerosis $(n=120)$, and those with cardiogenic embolisms $(n=153)$. Unusual causes of stroke were found in 16 patients: artery dissection $(n=8)$, air embolism $(n=3)$, and iatrogenic stroke due to coronary angiography $(n=5)$. The remaining patients $(n=186)$ were defined as having ischaemic stroke of unknown origin unless the stroke origin could not be classified due to lack of routine diagnostic information. In some patients ( $\mathrm{n}=37$ ), TOE could not be performed because of absent consent or possible intolerability of the test. Some subjects $(n=10)$ were transferred elsewhere. We ultimately included a consecutive series of 149 patients who had first-ever strokes prior to 
the onset of cerebral infarction, i.e. prestroke independence equivalent to a modified Rankin Scale (mRS) score of $\leq 1$.

Age, sex, risk factors, and TOE findings, including degrees of AAPs, were assessed in 149 patients with stroke. These clinical characteristics were then compared between the patients with mRS scores of $\leq 2$ (good outcomes) and those with mRS scores of $>2$ (poor outcomes). This study was performed in accordance with the Declaration of Helsinki. The patients and their families provided written informed consent to undergo TOE, which was approved by the Ethics Committee of Nippon Medical School Hospital. The National Institutes of Health Stroke Scale (NIHSS) score at admission strongly predicts the likelihood of patient recovery after stroke; a score of $\leq 6$ at admission forecasts good recovery [20]. Therefore, we divided the patients into those with NIHSS scores of $\leq 6$ and those with scores of $>6$ at admission.

\section{Risk Factor Analysis}

Hypertension, diabetes mellitus, and dyslipidaemia were diagnosed by internal medicine specialists. Hypertension was diagnosed if subjects were taking antihypertensive agents or had a systolic blood pressure of $\geq 140 \mathrm{~mm} \mathrm{Hg}$ or diastolic blood pressure of $\geq 90 \mathrm{~mm} \mathrm{Hg}$. Diabetes mellitus was diagnosed if subjects were taking oral antihyperglycaemic agents or insulin or if their fasting blood glucose level was $\geq 7 \mathrm{mmol} / \mathrm{l}$. Dyslipidaemia was diagnosed if subjects were taking dyslipidaemia medication or had a serum low-density lipoprotein cholesterol level of $\geq 3.62 \mathrm{mmol} / \mathrm{l}$, a triglyceride level of $\geq 1.69 \mathrm{mmol} / \mathrm{l}$, or a high-density lipoprotein cholesterol level of $<1.03 \mathrm{mmol} / \mathrm{l}$. Smoking status was recorded as non-smoker, current smoker, or ex-smoker (if they had quit at least 6 months before). Coronary heart disease was recorded as ischaemic heart disease or a history of ischaemic heart disease. We additionally performed 24-hour electrocardiography Holter monitoring after admission in all the patients to diagnose intermittent atrial fibrillation. The estimated glomerular filtration rate (eGFR) was calculated from serum creatinine $(\mathrm{Cr})$ on admission, and the patients were classified into two groups: the eGFR $<60 \mathrm{ml} / \mathrm{min} / 1.73 \mathrm{~m}^{2}$ group or the eGFR $\geq 60 \mathrm{ml} / \mathrm{min} / 1.73 \mathrm{~m}^{2}$ group. The eGFR was calculated using the following equation for Japanese patients [21]:

eGFR $\left(\mathrm{ml} / \mathrm{min} / 1.73 \mathrm{~m}^{2}\right)=194 \times \mathrm{Cr}^{-1.094} \times \mathrm{age}^{-0.287}$.

Because the Modification of Diet in Renal Disease formula requires stable renal function, patients with acute kidney injury were excluded from this study.

\section{Carotid Ultrasonography}

A LOGIQ S6 (GE Medical Systems) device with a 9-MHz linear probe was used during hospitalisation. The examiner was provided no clinical information prior to testing. The patients were examined in the supine position in a darkened room with their head in a neutral position or slightly inclined. Longitudinal and cross-sectional images of the common and internal carotid arteries were evaluated to examine the intima media thickness (IMT) via Doppler or two-dimensional duplex sonography. The maximum IMT of the carotid artery was defined as the greater IMT in the common carotid artery or as far as the bifurcation of the internal and external carotid arteries. In the present study, atherosclerotic plaque was defined as an IMT of $\geq 1.1 \mathrm{~mm}$, according to our previous study [22]. We actually examined the presence or absence of stenosis by routine carotid echography of the proximal internal carotid artery. Large-artery atherosclerosis was diagnosed if proximal internal carotid artery atherosclerosis of $>50 \%$ by North American Symptomatic Carotid Endarterectomy Trial criteria existed in the ipsilateral side of cerebral infarction, and this case was excluded, as seen in figure 1 [23]. Internal carotid narrowing of haemodynamic significance $(\geq 50 \%)$ also was defined as present if peak systolic velocities in the internal carotid artery were $\geq 150 \mathrm{~cm} / \mathrm{s}$ [24]. Internal carotid artery stenosis $(\geq 50 \%)$ of the contralateral internal carotid artery did 
Abe et al.: Aortic Arch Atherosclerosis in Ischaemic Stroke of Unknown Origin Affects Prognosis

Fig. 1. Flowchart of TOE for the identification of stroke patients. Patients were excluded if they had small-vessel occlusion, largeartery atherosclerosis, cardiogenic embolism, or an unusual cause of stroke, or if they did not undergo TOE.

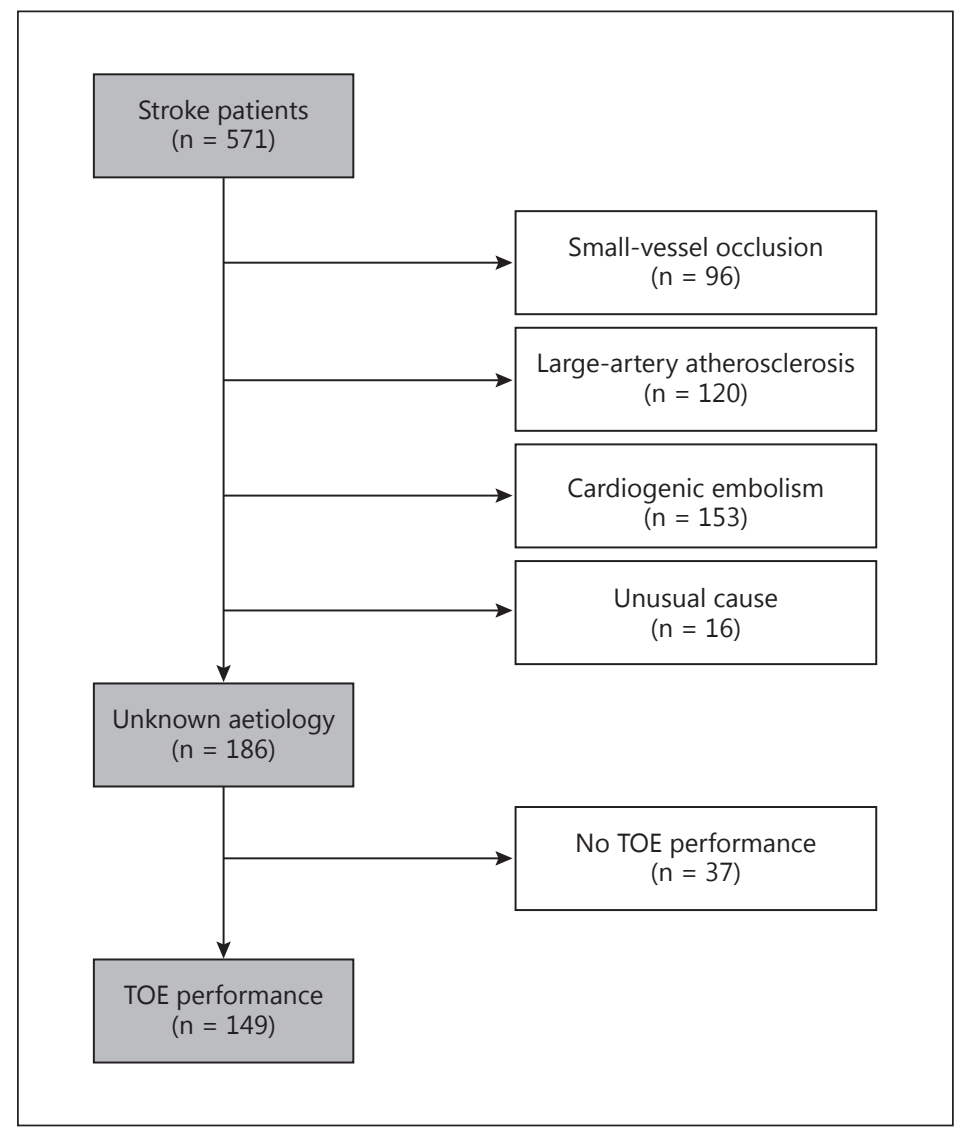

not occur, while there were only few cases of mild carotid artery stenosis (30-50\%). The maximal common carotid artery IMT measurement has already been shown to correlate well with cardiovascular risk in another study [25].

\section{TOE Study}

Awake patients underwent TOE via the LOGIQ S6 device (GE Medical Systems) with a 4to $7-\mathrm{MHz}$ wideband multiplanar probe. Lidocaine spray was applied, but the patients were not premedicated. Experienced sonographers conducted all examinations and recorded the findings on a Super-VHS videotape. After examination of the cardiac structures, including the presence of intracardiac thrombi, spontaneous echocontrast, patent foramen ovale (PFO), and atrial septal aneurysms, the transducer was gradually withdrawn to a location 20-35 cm from the incisors. The multiplanar probe was manipulated to provide appropriate views for axial and sagittal images throughout the aorta. The thickness of the plaques located in the aortic arch, which was defined as the portion of the aorta between the curve at the top of the descending aorta and the upper point of visibility, was determined by measuring the thickness of the intima media complex. AAPs $\geq 4 \mathrm{~mm}$ thick were defined as being large [26-30].

\section{Statistical Analysis}

Numerical values are presented as means \pm standard deviations (SDs). Baseline characteristics, vascular risk factors, and TOE findings were compared between the good and poor outcome groups. Data were statistically analysed using the $\chi^{2}$ test for categorical variables and the Kruskal-Wallis test for non-parametric variables. When the expected values were $<5$, 
Abe et al.: Aortic Arch Atherosclerosis in Ischaemic Stroke of Unknown Origin Affects Prognosis

Table 1. Baseline characteristics of patients

\begin{tabular}{lccc}
\hline & $\begin{array}{c}\text { mRS score } \leq 2 \\
(\mathrm{n}=110 ; 73.8 \%)\end{array}$ & $\begin{array}{c}\text { mRS score }>2 \\
(\mathrm{n}=39 ; 26.2 \%)\end{array}$ & $\mathrm{p}$ value \\
\hline Age, years & $67.3 \pm 14.4$ & $68.6 \pm 13.5$ & 0.612 \\
Age $>70$ years, $\mathrm{n}$ & $56(51 \%)$ & $18(46 \%)$ & 0.710 \\
Male, $\mathrm{n}$ & $68(62 \%)$ & $27(69 \%)$ & 0.444 \\
Hypertension, $\mathrm{n}$ & $72(65 \%)$ & $29(74 \%)$ & 0.327 \\
Diabetes mellitus, $\mathrm{n}$ & $28(25 \%)$ & $19(48 \%)$ & 0.009 \\
Dyslipidaemia, $\mathrm{n}$ & $62(56 \%)$ & $26(66 \%)$ & 0.343 \\
Current smoking, $\mathrm{n}$ & $36(33 \%)$ & $17(44 \%)$ & 0.246 \\
Coronary heart disease, $\mathrm{n}$ & $14(13 \%)$ & $6(15 \%)$ & 0.784 \\
Intermittent atrial fibrillation, $\mathrm{n}$ & $25(23 \%)$ & $7(18 \%)$ & 0.652 \\
eGFR, ml/min/1.73 ${ }^{2}$ & $69.9 \pm 25.0$ & $70.4 \pm 23.0$ & 0.897 \\
eGFR $\leq 60$ ml/min/1.73 m ${ }^{2}, \mathrm{n}$ & $35(32 \%)$ & $11(28 \%)$ & 0.840 \\
Baseline NIHSS score & $2.69 \pm 3.00$ & $6.48 \pm 5.66$ & $<0.001$ \\
Baseline NIHSS score $>6, \mathrm{n}$ & $9(8.1 \%)$ & $14(36 \%)$ & $<0.001$ \\
PFO, $\mathrm{n}$ & $58(53 \%)$ & $15(38 \%)$ & 0.139 \\
AAPs, mm & $4.51 \pm 2.28$ & $5.14 \pm 2.51$ & 0.174 \\
AAPs $\geq 4$ mm, $\mathrm{n}$ & $59(54 \%)$ & $29(74 \%)$ & 0.036 \\
Carotid artery IMT, mm & $1.90 \pm 1.01$ & $1.78 \pm 0.73$ & 0.408 \\
Carotid artery IMT $>1.1 \mathrm{~mm}, \mathrm{n}$ & $81(74 \%)$ & $28(72 \%)$ & 0.835 \\
Statin usage, $\mathrm{n}$ & $15(13 \%)$ & $6(15 \%)$ & 0.792 \\
\hline
\end{tabular}

Values denote means \pm SD unless specified otherwise. The $\chi^{2}$ test, the two-tailed Fisher exact test, and the Kruskal-Wallis test were used for comparison.

Fisher's exact test was used. Given that there were many independent variables, two-step regression strategies were pursued. First, forward stepwise regression was used with no forced independent variables unless otherwise mentioned, and $p=0.10$ indicated the criteria for entry and removal. The logistic regression model included selected factors that were determined from the forward stepwise regression. All data were analysed using JMP software, version 9.02, for Windows (SAS Institute Japan Inc., Tokyo, Japan). All analyses were twotailed, and $\mathrm{p}<0.05$ was considered statistically significant [9].

\section{Results}

Of the 571 patients, 149 who could undergo TOE were included in our retrospective analysis. Table 1 shows their baseline characteristics according to mRS scores 3 months later. Of the 149 patients with cerebral infarction of unknown origin at admission, $110(73.8 \%)$ and $39(26.2 \%)$ showed a good prognosis (mRS score $\leq 2)$ or a poor prognosis (mRS score $>2) 3$ months later, respectively. Once stratified by sex, 62 and $69 \%$ of the male patients were included in the good or poor prognosis group, respectively. The mean age was 67.3 years in the good prognosis group and 68.6 years in the poor prognosis group. There were no significant differences in age or sex between the groups.

Among the risk factors, a history of diabetes was more frequently observed in the poor prognosis group $(p=0.009)$. The baseline NIHSS scores were 2.69 and 6.48 in the good and poor prognosis groups, respectively. Baseline NIHSS scores were significantly higher in the poor prognosis group $(\mathrm{p}<0.001)$. There were significantly more patients with baseline NIHSS scores of $>6$ in the poor prognosis group than in the good prognosis group (36 vs. 8.1\%; $<<$ 


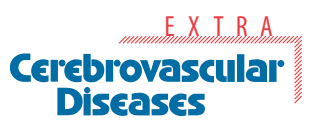

Table 2. Logistic regression analysis for poor outcome ( $m R S$ score $>2$ ) at 3 months after ischaemic stroke

\begin{tabular}{|c|c|c|c|}
\hline \multicolumn{4}{|c|}{ Cerebrovasc Dis Extra 2014;4:92-101 } \\
\hline \multicolumn{2}{|c|}{ DOI: 10.1159/000362434 } & & $\begin{array}{l}\text { (c) } 2014 \text { S. Karger AG, Basel } \\
\text { www.karger.com/cee }\end{array}$ \\
\hline \multicolumn{4}{|c|}{$\begin{array}{l}\text { Abe et al.: Aortic Arch Atherosclerosis in Ischaemic Stroke of Unknown Origin Affects } \\
\text { Prognosis }\end{array}$} \\
\hline & OR & $95 \% \mathrm{CI}$ & $\mathrm{p}$ value \\
\hline NIHSS score $>6$ & 6.77 & $2.59-18.8$ & $<0.001$ \\
\hline AAPs $\geq 4 \mathrm{~mm}$ & 2.75 & $1.19-6.91$ & 0.024 \\
\hline
\end{tabular}

Logistic regression analysis based on the maximum likelihood ratio for age, sex, hypertension, diabetes mellitus, dyslipidaemia, smoking, coronary heart disease, intermittent atrial fibrillation, eGFR, NIHSS score, PFO, AAPs, and carotid artery IMT. Whole model test at $\mathrm{p}<$ 0.0001 .

0.001). Although there was no significant difference in AAPs as an indicator of arteriosclerosis between the groups (good prognosis: $4.51 \mathrm{~mm}$; poor prognosis: $5.14 \mathrm{~mm}$ ), the number of patients with AAPs of $\geq 4 \mathrm{~mm}$ was significantly larger in the poor prognosis group than in the good prognosis group ( 74 vs. $54 \%$; $=0.036$ ). There were no significant differences in PFO, carotid artery IMT $<1.1 \mathrm{~mm}$, or statin usage between the good and poor prognosis groups (table 1).

For the poor prognosis group, to estimate the risk factors for a poor outcome after 3 months, the following variables were selected for logistic regression analysis: age, sex, hypertension, diabetes, dyslipidaemia, intermittent atrial fibrillation, eGFR, baseline NIHSS score, PFO occurrence, AAPs, and carotid artery IMT. A baseline NIHSS score of $>6$ [odds ratio $(\mathrm{OR})=6.77 ; 95 \%$ confidence interval (CI): 2.59-18.8; $\mathrm{p}<0.001$ ] and AAPs of $\geq 4 \mathrm{~mm}$ (OR = 2.75; 95\% CI: 1.19-0.91; $\mathrm{p}=0.024$ ) were the independent factors associated with poor prognosis (table 2).

\section{Discussion}

Here, we examined the factors associated with poor prognosis of first-ever cerebral infarction of unknown origin. For the factors associated with a poor prognosis after cerebral infarction, a systemic review by Veerbeek et al. [31] reported on age and NIHSS score at admission; this information was obtained from six high-quality studies [4-8, 32]. In our study, the bivariate analysis showed that diabetes, an NIHSS score of $>6$ at admission, and AAPs of $\geq 4 \mathrm{~mm}$ were significantly and frequently combined in the poor prognosis group and that the NIHSS score at admission was significantly higher in the poor prognosis group. Arteriosclerosis of the aortic arch and PFO (factors obtained from TOE) were included in this analysis, and logistic analysis was conducted using these factors as well as age, sex, hypertension, diabetes, dyslipidaemia, history of current smoking, intermittent atrial fibrillation, eGFR $<60$ $\mathrm{ml} / \mathrm{min} / 1.73 \mathrm{~m}^{2}$, baseline NIHSS score, and carotid artery IMT. As a result, although a significant association was found in the poor prognosis group with an NIHSS score of $>6$ on admission and AAPs of $\geq 4 \mathrm{~mm}$, there was no significant association with age. In general, age has not been a predictor of poor prognosis $[4,6,32,33]$.

Additionally, risk factors such as intermittent atrial fibrillation (which can cause cardiogenic embolism; $21.4 \%$ of all the subjects in this study) and PFO (which can cause cryptogenic stroke; $48.9 \%$ of all the subjects in this study) were not associated with prognosis. Earlier studies have also shown no association between atrial fibrillation and prognosis [5, 7, 33], and no reports have indicated an association between PFO and prognosis. 

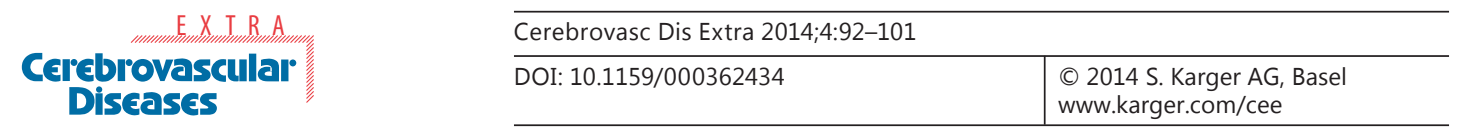

Abe et al.: Aortic Arch Atherosclerosis in Ischaemic Stroke of Unknown Origin Affects Prognosis

The present study, which used arteriosclerosis of the aortic arch and PFO as factors obtained from TOE, showed a significant association between large plaques and prognosis. An earlier autopsy study reported that large plaques $(\geq 4 \mathrm{~mm})$ were commonly found in the aortic arch of the chest in patients with cerebral infarction of unknown origin [13]. However, our study is the first to show that large plaques are related to patient prognosis after cerebral infarction of unknown origin. Thickening of the chest aortic arch $(\geq 4 \mathrm{~mm})$ is a clinical condition that has attracted attention because it has already been shown to be involved not only in first-ever cerebral infarction [14-16] but also in cerebral infarction recurrence [18], with an increased risk of death $[17,18]$.

Although the diagnostic criteria for aortogenic embolism have been completely established, cerebral infarction is believed to be associated with arteriosclerosis of the aortic arch $(\geq 4 \mathrm{~mm})$. One report stated that as arteriosclerosis of the aortic arch thickened and mobile aortic plaques became more prevalent, the number of multiple infarctions that significantly extended to multiple vascular regions increased [27]. Fujimoto et al. [34] reported that aortogenic embolism, cardiogenic embolism, and paradoxical cerebral embolism could easily cause multiple brain lesions, and that they accounted for $20-31 \%$ in a series of 270 patients with cortical or subcortical cerebral infarctions. Therefore, aortogenic embolism is likely to cause multiple brain lesions, although we cannot conclude with certainty at this time that aortogenic embolism influences the prognosis of cerebral infarction of unknown origin.

In a retrospective study of 486 patients treated with tissue plasminogen activator in a single institution, patients with paradoxical cerebral embolisms had a significantly lower frequency of poor outcomes at hospital discharge than patients with other forms of cerebral infarction [35]. This study examined tissue plasminogen activator treatment, but it is generally believed that patients with paradoxical cerebral embolisms have good prognoses. The reason for this belief is that thrombus clots within the deep venous system can be fibrin rich and freely soluble in patients with paradoxical cerebral embolisms [36, 37].

Naess et al. [38] reported that thrombolytic therapy was more effective in patients with intermittent atrial fibrillation than in those with chronic atrial fibrillation. It was suggested that thrombi might have been relatively recently formed in patients with intermittent atrial fibrillation, which might have caused early recanalisation, leading to a good short-term prognosis. In contrast, an embolus from the aortic wall is typically an atherosclerotic plaque consisting of a lipid pool, fibrous cap, smooth muscle cells, mononuclear cells, and calcifications [16, 39]. In particular, these emboli include high contents of lipids, mononuclear leucocytes, and macrophages [39]. Therefore, it might be difficult to achieve spontaneous dissolution and recanalisation in this type of embolus compared with so-called fibrin-rich thrombi.

Di Tullio et al. [17] enrolled 209 stroke-free subjects who were over the age of 50 years and available to undergo TOE. Thus, the incidental detection of plaques in the aortic arch or proximal descending aorta was not associated with future vascular events [40]. However, a retrograde flow in the distal aortic arch and descending aorta can connect with the left subclavian artery, left carotid artery, and brachiocephalic trunk (in this order), causing embolic stroke in these vascular territories $[41,42]$. The degree of retrograde flow varies in a normal population and is enhanced by age and aortic valve insufficiency [41,43]. In the present study, which focussed on cerebral infarction of unknown origin, embolic stroke could have been induced by some of the AAPs via retrograde flow.

Large AAPs $\geq 4 \mathrm{~mm}$ in thickness are associated with ischaemic stroke of unknown cause, stroke recurrence, and all vascular events $[13,17]$. The complex morphologic features of AAPs, including mobile or ulcerated aortic plaques, have also been closely linked to cryptogenic stroke $[17,27,44]$. The numbers of cases of mobility and ulceration were only $2(1.3 \%)$ and $7(4.7 \%)$, respectively. However, mobility and ulceration can become risk factors for the occurrence and recurrence of brain infarction. Hypoechoic and irregularly shaped plaques 
can also cause stenosis, but the incidence thereof varies depending on the examiner, as well as on the echo apparatus used. However, these plaques account for approximately $9 \%$ of the total. Thus, these cases might have influenced the results of the present study.

This study has some limitations. First, the study was based on a cross-sectional design, and the subjects were classified as having a broad category of cerebral infarction of unknown origin. Another limitation was that patients with cerebral infarction of unknown origin in a conventional sense were not included in this study to prevent selection bias; they might have had cerebral infarctions caused by atrial fibrillation and PFO and were intentionally excluded from the TOE group. However, it was impossible to avoid a selection bias because not all the patients underwent TOE. Because this study was performed retrospectively, a prospective case-control study could answer the question of whether arteriosclerosis of the aortic arch contributes to cerebral infarction of unknown origin (and thus to prognosis).

It is important to obtain information about AAPs using TOE, which assists in predicting the prognoses of patients in whom cerebral infarction of unknown origin is diagnosed at admission. Despite these limitations, TOE is useful in establishing the clinical diagnostic criteria for aortogenic brain embolisms.

\section{Disclosure Statement}

The authors have no conflicts of interest to disclose.

\section{References}

1 Miller EL, Murray L, Richards L, Zorowitz RD, Bakas T, Clark P, Billinger SA: Comprehensive overview of nursing and interdisciplinary rehabilitation care of the stroke patient: a scientific statement from the American Heart Association. Stroke 2010;41:2402-2448.

-2 Thrift AG, Dewey HM, Macdonell RA, McNeil JJ, Donnan GA: Incidence of the major stroke subtypes: initial findings from the North East Melbourne Stroke Incidence Study (NEMESIS). Stroke 2001;32:1732-1738.

-3 Feigin VL, Lawes CM, Bennett DA, Anderson CS: Stroke epidemiology: a review of population-based studies of incidence, prevalence, and case-fatality in the late 20th century. Lancet Neurol 2003;2:43-53.

4 Reid JM, Gubitz GJ, Dai D, Kydd D, Eskes G, Reidy Y, Christian C, Counsell CE, Dennis M, Phillips SJ: Predicting functional outcome after stroke by modelling baseline clinical and CT variables. Age Ageing 2010;39:360-366.

5 Fiorelli M, Alperovitch A, Argentino C, Sacchetti ML, Toni D, Sette G, Cavalletti C, Gori MC, Fieschi C: Prediction of long-term outcome in the early hours following acute ischemic stroke. Italian Acute Stroke Study Group. Arch Neurol 1995;52:250-255.

6 Johnston KC, Wagner DP, Wang XQ, Newman GC, Thijs V, Sen S, Warach S: Validation of an acute ischemic stroke model: does diffusion-weighted imaging lesion volume offer a clinically significant improvement in prediction of outcome? Stroke 2007;38:1820-1825.

7 Sato S, Toyoda K, Uehara T, Toratani N, Yokota C, Moriwaki H, Naritomi H, Minematsu K: Baseline NIH Stroke Scale score predicting outcome in anterior and posterior circulation strokes. Neurology 2008;70:2371-2377.

8 Weimar C, Ziegler A, Konig IR, Diener HC: Predicting functional outcome and survival after acute ischemic stroke. J Neurol 2002;249:888-895.

-9 Clavier I, Hommel M, Besson G, Noelle B, Perret JE: Long-term prognosis of symptomatic lacunar infarcts: a hospital-based study. Stroke 1994;25:2005-2009.

10 Protopsaltis J, Kokkoris S, Korantzopoulos P, Milionis HJ, Karzi E, Anastasopoulou A, Filioti K, Antonopoulos S, Melidonis A, Giannoulis G: Prediction of long-term functional outcome in patients with acute ischemic nonembolic stroke. Atherosclerosis 2009;203:228-235.

-11 Sobrino T, Hurtado O, Moro MA, Rodriguez-Yanez M, Castellanos M, Brea D, Moldes O, Blanco M, Arenillas JF, Leira R, Davalos A, Lizasoain I, Castillo J: The increase of circulating endothelial progenitor cells after acute ischemic stroke is associated with good outcome. Stroke 2007;38:2759-2764.

12 Schulz UG, Rothwell PM: Differences in vascular risk factors between etiological subtypes of ischemic stroke: importance of population-based studies. Stroke 2003;34:2050-2059.

13 Amarenco P, Cohen A, Tzourio C, Bertrand B, Hommel M, Besson G, Chauvel C, Touboul PJ, Bousser MG: Atherosclerotic disease of the aortic arch and the risk of ischemic stroke. N Engl J Med 1994;331:1474-1479. 
Abe et al.: Aortic Arch Atherosclerosis in Ischaemic Stroke of Unknown Origin Affects Prognosis

14 Di Tullio MR, Sacco RL, Gersony D, Nayak H, Weslow RG, Kargman DE, Homma S: Aortic atheromas and acute ischemic stroke: a transesophageal echocardiographic study in an ethnically mixed population. Neurology 1996;46:1560-1566.

15 Tunick PA, Rosenzweig BP, Katz ES, Freedberg RS, Perez JL, Kronzon I: High risk for vascular events in patients with protruding aortic atheromas: a prospective study. J Am Coll Cardiol 1994;23:1085-1090.

16 Amarenco P, Duyckaerts C, Tzourio C, Henin D, Bousser MG, Hauw JJ: The prevalence of ulcerated plaques in the aortic arch in patients with stroke. N Engl J Med 1992;326:221-225.

17 Di Tullio MR, Russo C, Jin Z, Sacco RL, Mohr JP, Homma S: Aortic arch plaques and risk of recurrent stroke and death. Circulation 2009;119:2376-2382.

18 Atherosclerotic disease of the aortic arch as a risk factor for recurrent ischemic stroke. The French Study of Aortic Plaques in Stroke Group. N Engl J Med 1996;334:1216-1221.

19 Adams HP Jr, Bendixen BH, Kappelle LJ, Biller J, Love BB, Gordon DL, Marsh EE 3rd: Classification of subtype of acute ischemic stroke: definitions for use in a multicenter clinical trial. TOAST. Trial of Org 10172 in Acute Stroke Treatment. Stroke 1993;24:35-41.

20 Adams HP Jr, Davis PH, Leira EC, Chang KC, Bendixen BH, Clarke WR, Woolson RF, Hansen MD: Baseline NIH Stroke Scale score strongly predicts outcome after stroke: a report of the Trial of Org 10172 in Acute Stroke Treatment (TOAST). Neurology 1999;53:126-131.

-21 Matsuo S, Imai E, Horio M, Yasuda Y, Tomita K, Nitta K, Yamagata K, Tomino Y, Yokoyama H, Hishida A: Revised equations for estimated GFR from serum creatinine in Japan. Am J Kidney Dis 2009;53:982-992.

-22 Handa N, Matsumoto M, Maeda H, Hougaku H, Ogawa S, Fukunaga R, Yoneda S, Kimura K, Kamada T: Ultrasonic evaluation of early carotid atherosclerosis. Stroke 1990;21:1567-1572.

-23 North American Symptomatic Carotid Endarterectomy Trial: methods, patient characteristics, and progress. Stroke 1991;22:711-720.

24 Wang TJ, Nam BH, Wilson PW, Wolf PA, Levy D, Polak JF, D’Agostino RB, O’Donnell CJ: Association of C-reactive protein with carotid atherosclerosis in men and women: the Framingham Heart Study. Arterioscler Thromb Vasc Biol 2002;22:1662-1667.

-25 Bots ML, Evans GW, Riley WA, Grobbee DE: Carotid intima-media thickness measurements in intervention studies: design options, progression rates, and sample size considerations - a point of view. Stroke 2003;34: 2985-2994.

-26 Stone DA, Hawke MW, LaMonte M, Kittner SJ, Acosta J, Corretti M, Sample C, Price TR, Plotnick GD: Ulcerated atherosclerotic plaques in the thoracic aorta are associated with cryptogenic stroke: a multiplane transesophageal echocardiographic study. Am Heart J 1995;130:105-108.

27 Ueno Y, Kimura K, Iguchi Y, Shibazaki K, Inoue T, Hattori N, Urabe T: Mobile aortic plaques are a cause of multiple brain infarcts seen on diffusion-weighted imaging. Stroke 2007;38:2470-2476.

-28 Cohen A, Tzourio C, Bertrand B, Chauvel C, Bousser MG, Amarenco P: Aortic plaque morphology and vascular events: a follow-up study in patients with ischemic stroke. FAPS Investigators. French Study of Aortic Plaques in Stroke. Circulation 1997;96:3838-3841.

29 Dee W, Geibel A, Kasper W, Konstantinides S, Just H: Mobile thrombi in atherosclerotic lesions of the thoracic aorta: the diagnostic impact of transesophageal echocardiography. Am Heart J 1993;126:707-710.

-30 Yoshimura S, Toyoda K, Kuwashiro T, Koga M, Otsubo R, Konaka K, Naganuma M, Matsuoka H, Naritomi H, Minematsu K: Ulcerated plaques in the aortic arch contribute to symptomatic multiple brain infarction. J Neurol Neurosurg Psychiatry 2010;81:1306-1311.

-31 Veerbeek JM, Kwakkel G, van Wegen EE, Ket JC, Heymans MW: Early prediction of outcome of activities of daily living after stroke: a systematic review. Stroke 2011;42:1482-1488.

-32 Weimar C, Roth M, Willig V, Kostopoulos P, Benemann J, Diener HC: Development and validation of a prognostic model to predict recovery following intracerebral hemorrhage. J Neurol 2006;253:788-793.

-33 Censori B, Camerlingo M, Casto L, Ferraro B, Gazzaniga GC, Cesana B, Mamoli A: Prognostic factors in first-ever stroke in the carotid artery territory seen within 6 hours after onset. Stroke 1993;24:532-535.

-34 Fujimoto S, Toyoda K, Jinnouchi J, Yasaka M, Kitazono T, Okada Y: Differences in diffusion-weighted image and transesophageal echocardiographical findings in cardiogenic, paradoxical and aortogenic brain embolism. Cerebrovasc Dis 2011;32:148-154.

35 Chang JJ, Chiem T, Alderazi YJ, Chapple K, Restrepo L: Clinical outcomes after intravenous fibrinolysis in cryptogenic strokes with or without patent foramen ovale. J Stroke Cerebrovasc Dis 2013;22:e492-e499.

-36 Gaffney PJ, Whitaker AN: Fibrin crosslinks and lysis rates. Thromb Res 1979;14:85-94.

37 Kimura K, Iguchi Y, Shibazaki K, Terasawa Y, Aoki J, Matsumoto N: The presence of a right-to-left shunt is associated with dramatic improvement after thrombolytic therapy in patients with acute ischemic stroke. Stroke 2009;40:303-305.

-38 Naess H, Waje-Andreassen U, Thomassen L: Persistent atrial fibrillation is associated with worse prognosis than paroxysmal atrial fibrillation in acute cerebral infarction. ISRN Cardiol 2012;2012:650915.

-39 Davies MJ, Richardson PD, Woolf N, Katz DR, Mann J: Risk of thrombosis in human atherosclerotic plaques: role of extracellular lipid, macrophage, and smooth muscle cell content. Br Heart J 1993;69:377-381.

40 Russo C, Jin Z, Rundek T, Homma S, Sacco RL, di Tullio MR: Atherosclerotic disease of the proximal aorta and the risk of vascular events in a population-based cohort: the Aortic Plaques and Risk of Ischemic Stroke (APRIS) study. Stroke 2009;40:2313-2318. 
41 Harloff A, Strecker C, Dudler P, Nussbaumer A, Frydrychowicz A, Olschewski M, Bock J, Stalder AF, Stroh AL, Weiller C: Retrograde embolism from the descending aorta visualization by multidirectional 3D velocity mapping in cryptogenic stroke. Stroke 2009;40:1505-1508.

$\checkmark 42$ Harloff A, Simon J, Brendecke S, Assefa D, Helbing T, Frydrychowicz A, Weber J, Olschewski M, Strecker C, Hennig J: Complex plaques in the proximal descending aorta an underestimated embolic source of stroke. Stroke 2010;41:1145-1150.

-43 Reimold SC, Maier SE, Aggarwal K, Fleischmann KE, Piwnica-Worms D, Kikinis R, Lee RT: Aortic flow velocity patterns in chronic aortic regurgitation: implications for Doppler echocardiography. J Am Soc Echocardiogr 1996;9:675-683.

-44 Capmany RP, Ibañez MO, Pesquer XJ: Complex atheromatosis of the aortic arch in cerebral infarction. Curr Cardiol Rev 2010;6:184. 